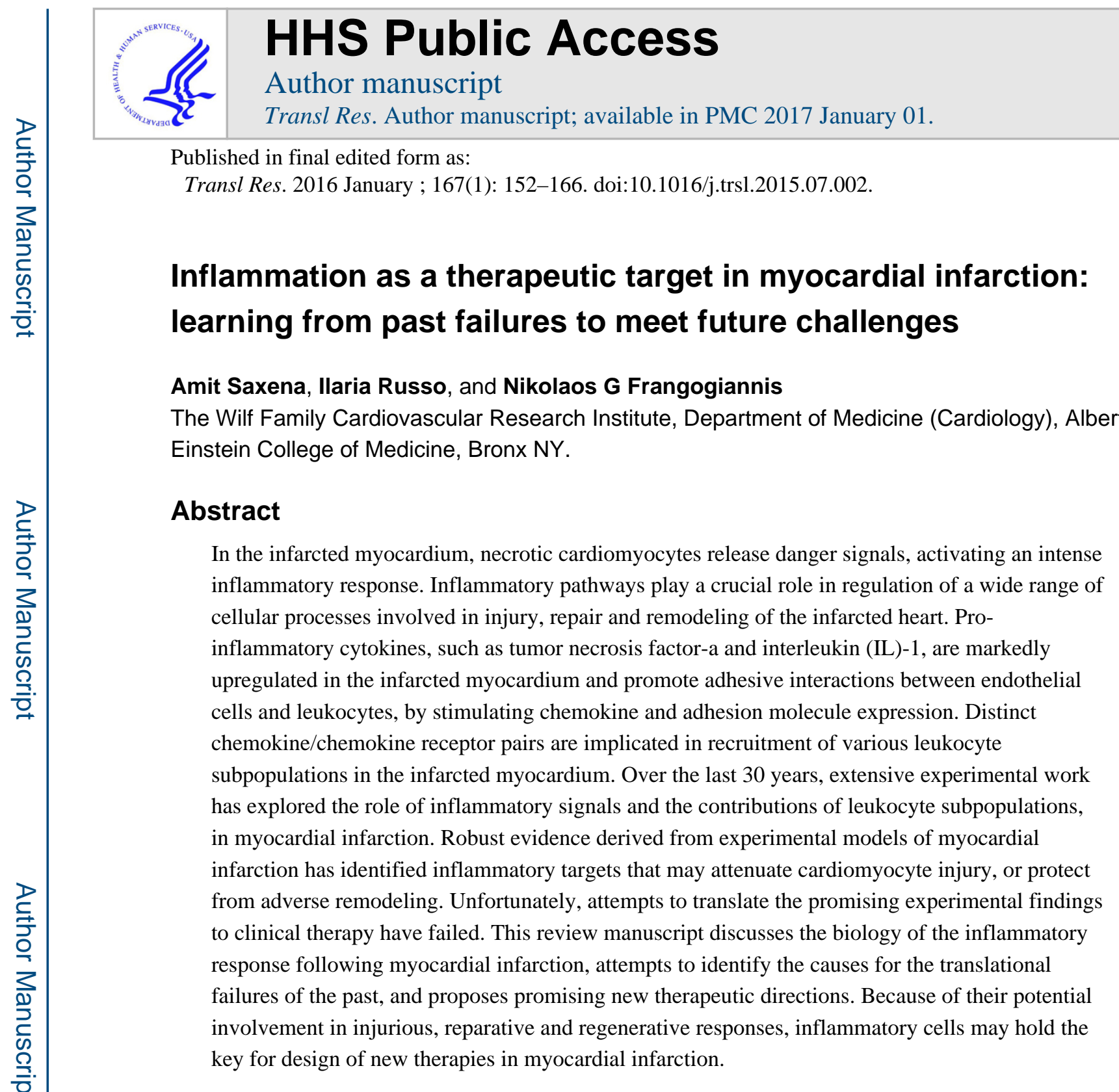

\title{
INTRODUCTION
}

In myocardial infarction, coronary artery occlusion causes ischemia of the territory subserved by the vessel, eventually leading to death of up to a billion cardiomyocytes (1). The adult mammalian heart has negligible regenerative capacity; thus, acute myocardial infarction is associated with loss of a large amount of myocardium that is replaced by a collagen-based scar. Necrosis of ischemic cardiomyocytes triggers an intense inflammatory

\footnotetext{
Corresponding author: Nikolaos Frangogiannis, MD. Department of Medicine (Cardiology), The Wilf Family Cardiovascular Research Institute, Albert Einstein College of Medicine 1300 Morris Park Avenue Forchheimer G46B, Bronx NY 10461. Tel: 718-430-3546. Fax: 718-430-8989.nikolaos.frangogiannis@einstein.yu.edu.

Publisher's Disclaimer: This is a PDF file of an unedited manuscript that has been accepted for publication. As a service to our customers we are providing this early version of the manuscript. The manuscript will undergo copyediting, typesetting, and review of the resulting proof before it is published in its final citable form. Please note that during the production process errors may be discovered which could affect the content, and all legal disclaimers that apply to the journal pertain.

The authors have no conflicts to disclose. All authors have reviewed and approved the manuscript, and have read the journal's policy on disclosure of potential conflicts of interest and the journal's authorship agreement.
} 
reaction that serves to clear the wound from dead cells and matrix debris, and contributes to formation of a collagen-based scar (2). Abundant leukocytes infiltrate the infarcted myocardium and are predominantly localized in the infarct border zone where they may interact with viable cardiomyocytes. In the 1980s and 1990s a large body of experimental evidence suggested that inflammatory leukocytes may extend ischemic injury, exerting potent cytotoxic effects on border zone cardiomyocytes (3). These observations generated significant enthusiasm regarding the potential use of targeted anti-inflammatory strategies to reduce infarct size and to attenuate injury following myocardial infarction. Unfortunately, clinical trials inhibiting leukocyte integrins and the complement cascade in order to attenuate post-infarction inflammation were disappointing (4),(5). The failures of the clinical studies markedly dampened enthusiasm regarding the translational potential of the field. This is unfortunate, because inflammatory signaling is implicated in repair and remodeling of the infarcted heart. Thus, targeting inflammatory mediators may exert beneficial actions by attenuating dilative remodeling of the infarcted heart. Moreover, recent observations suggesting cytoprotective and regenerative actions of inflammatory signals have (once again) fueled interest in the field.

This review manuscript deals with the potential role of the inflammatory cascade as a therapeutic target in myocardial infarction. After a brief overview of the cellular effectors and molecular signals implicated in the post-infarction inflammatory reaction, we will discuss promising therapeutic approaches targeting the inflammatory response. Dissection of the molecular signals regulating induction and resolution of post-infarction inflammation needs to be complemented by understanding of the pathophysiologic complexity of the clinical context, in order to design effective therapeutic approaches for patients with myocardial infarction.

\section{THE INFLAMMATORY RESPONSE IN MYOCARDIAL INFARCTION}

Healing of the infarcted heart can be divided in three distinct but overlapping phases: the inflammatory phase, the proliferative phase and the maturation phase (6). During the inflammatory phase, danger signals (alarmins) released from dying cardiomyocytes activate innate immune pathways inducing chemokine and cytokine synthesis, and stimulating adhesion molecule expression on vascular endothelial cells (Figure 1). Experimental studies have suggested that high mobility group box-1 (HMGB1), heat shock proteins, adenosine, extracellular RNA, matrix fragments, and Interleukin (IL)-1a released from necrotic cardiomyocytes may stimulate the innate immune response initiating the post-infarction inflammatory cascade (7),(8),(9),(10). The relative role of specific cardiomyocyte-derived alarmins in activation of the post-infarction inflammatory response remains unknown. Alarmins released by necrotic cells activate toll-like receptor (TLR) and receptor for advanced glycation end-products (RAGE)-dependent pathways in vascular endothelial cells, immune cells and fibroblasts inducing synthesis of chemokines and cytokines (11),(12). Activation of the complement cascade is also prominent in the infarcted heart and stimulates downstream pro-inflammatory pathways (13),(14),(15). Pro-inflammatory cytokines, such as Tumor Necrosis Factor (TNF)- a, IL-1 $\beta$ and IL-6, released by leukocytes, fibroblasts, endothelial cells and cardiomyocytes induce adhesion molecule and chemokine synthesis promoting recruitment of leukocytes into the infarcted area (16),(17),(18). IL-1 signaling 
plays a central role in activation of the post-infarction inflammatory reaction, stimulating chemokine expression by leukocytes and fibroblasts (19), while preventing premature conversion of the abundant cardiac fibroblasts into matrix-synthetic myofibroblasts (20). The inflammasome, a molecular platform that triggers caspase-1 activation and mediates subsequent cleavage of active pro-IL-1 $\beta$ into IL- $1 \beta$, plays an important role in generation of bioactive IL-1 in the infarct. In vivo evidence has demonstrated that activation of the inflammasome is localized in both cardiomyocytes and interstitial cells in the infarcted heart (21), (22).

Chemokine upregulation is a hallmark of the post-infarction inflammatory response and mediates recruitment of pro-inflammatory leukocyte subsets in the infarcted heart (23). CXC chemokines containing the Glu-Leu-Arg sequence (the ELR motif), such as CXCL8/IL-8, are secreted in the infarct (24), and stimulate recruitment of neutrophils, whereas CC chemokines, such as monocyte chemoattractant protein-(MCP)-1/CCL2 and CCL7, mediate recruitment of pro-inflammatory monocytes (25),(26),(27). Infiltrating leukocytes phagocytose dead cells and matrix debris and set the stage for activation of reparative cells.

Apoptosis of infiltrating neutrophils marks the end of the inflammatory phase. Professional phagocytes clear the infarct from apoptotic cells (28),(29); this process known as efferocytosis, is associated with release of anti-inflammatory cytokines, such as IL-10 and Transforming Growth Factor (TGF)- $\beta$, and may play an important role in suppression of the post-infarction inflammatory response. In addition to the role of secreted anti-inflammatory mediators, activation of endogenous intracellular signals that restrain the immune response (such as Interleukin-receptor associated kinase-M) suppresses pro-inflammatory cascades in the healing infarct (30).

Suppression of inflammatory signaling and resolution of the inflammatory infiltrate are dependent on infiltration of the infarct with inhibitory leukocyte subsets, such as antiinflammatory monocyte subpopulations (31) and regulatory T cells (32),(33). Moreover, modulation of cardiac macrophages towards an anti-inflammatory phenotype may contribute to suppression of inflammatory cytokine and chemokine expression (34),(35). Surviving cardiomyocytes in the infarct border zone may also limit inflammation by secreting mediators with anti-inflammatory properties (29),(36). Because unrestrained activity, temporal prolongation, or spatial expansion of the inflammatory reaction result in accentuated cardiac remodeling and worse dysfunction, defective negative regulation of the post-infarction inflammatory response may be implicated in the pathogenesis of heart failure in patients surviving an acute myocardial infarction (Figure 2) (37).

As pro-inflammatory signaling is suppressed, activated myofibroblasts become the predominant cell type in the healing infarct. Infarct myofibroblasts are phenotypically modulated fibroblasts, primarily localized in the infarct border zone that express contractile proteins (such as a-smooth muscle actin and the embryonal isoform of smooth muscle myosin) $(38,39)$, but do not synthesize the SM1 and SM2 isoforms of smooth muscle myosin heavy chain (38). Their origin is debated: proliferation and activation of resident fibroblast populations, endothelial to mesenchymal transdifferentiation, recruitment of circulating and resident fibroblast progenitors and modulation of cardiac pericytes have been 
proposed as potential sources for the abundant myofibroblasts in the infarct border zone. Recent lineage-tracing studies have suggested that resident epicardium-derived fibroblasts may be the main source of myofibroblasts in healing myocardial scars (40). Infarct myofibroblasts secrete both structural and matricellular proteins in the healing infarct. Deposition of structural matrix proteins (such as collagens) preserves the integrity and geometry of the ventricle. On the other hand, incorporation of matricellular proteins into the matrix network plays an important role in transducing cytokine and growth factor-mediated signals from the cardiac interstitium to the cellular elements, thus contributing to the plasticity of the infarct environment (41),(42),(43),(44). The renin-angiotensin-aldosterone system, TGF- $\beta$, Platelet-Derived Growth Factor (PDGF) and the mast cell-derived proteases tryptase and chymase play an important role in activating fibroblasts in the healing infarct (45),(46),(47),(48).

During the maturation phase, proliferative activity of the fibroblasts is suppressed and deposition of new matrix proteins is inhibited. Little is known regarding the pathways and inhibitory signals that terminate the fibrotic response in the infarct. During the inflammatory and proliferative phase of infarct healing, the anti-fibrotic chemokine interferon- $\gamma$ inducible protein (IP)-10/CXCL10 is upregulated in the infarcted area and inhibits fibroblast migration, preventing an overactive fibrotic response (49),(50). Whether, IP-10 or other antifibrotic mediators are involved in scar maturation remains unknown. As the scar matures, the collagenous matrix is cross-linked and reparative infarct myofibroblasts become quiescent, or may undergo apoptosis. However, in large infarcts, interstitial cell activation persists in the infarct border zone and in remodeling non-infarcted myocardial segments, likely reflecting regional alterations of the cardiac mechanics due to loss of contractile myocardium, and the effects of pressure and volume overload on the surviving myocardium.

\section{TARGETING INFLAMMATION IN MYOCARDIAL INFARCTION. LESSONS FROM PAST TRANSLATIONAL FAILURES}

\section{The concept of cytotoxic inflammatory injury}

Several observations fueled the notion that inflammation may extend ischemic injury following myocardial infarction. First, the idea that the inflammatory reaction triggered to clear the infarcted heart from dead cells may be inherently overactive for the delicate requirements of the myocardium. Inflammatory cascades did not evolve to protect the injured heart. In most species, cardiovascular disease is an uncommon cause of death. In humans, heart disease is a major cause of morbidity and mortality; however, myocardial infarction occurs past the reproductive age and would not be expected to impose any evolutionary pressures on the inflammatory cascade. Thus, inflammatory processes evolved as a response to traumatic injury and as a protective shield from pathogenic organisms, and may be excessive for the sterile environment of the infarcted heart (51). Second, in the infarcted myocardium, leukocytes infiltrate the viable border zone, where they may interact with surviving cardiomyocytes. Through the production of proteases, cytokines and reactive oxygen species, neutrophils and pro-inflammatory monocytes may exert cytotoxic actions on viable cardiomyocytes extending ischemic injury. In a large animal model of reperfused myocardial infarction, neutrophil depletion was reported to reduce infarct size by more than 
$40 \%$, providing strong support for a leukocyte-driven mechanism responsible for extension of ischemic injury (52). The deleterious effects of neutrophils on cardiomyocytes were supported by in vitro evidence suggesting that activated neutrophils adhere to stimulated cardiomyocytes through integrin/intercellular adhesion molecule (ICAM)-1 interactions, and induce oxidative injury (3). It should be noted that experimental evidence did not consistently support the deleterious effects of the neutrophils in accentuating cardiomyocyte death following myocardial ischemia, as neutrophil depletion studies failed, in some cases, to reduce infarct size (53). Thus, the role of the neutrophils in extending ischemic myocardial injury has remained controversial (54).

\section{Broad-range anti-inflammatory strategies may have catastrophic consequences on repair of the infarcted heart}

If inflammation extends ischemic injury, broad inhibition of the inflammatory response with corticosteroids or non-steroidal anti-inflammatory drugs (NSAIDs) could confer significant protection to the infarcted myocardium. It should be noted that the therapeutic use of corticosteroids in acute myocardial infarction was proposed before the development of the inflammatory injury hypothesis, based on experimental studies suggesting protective actions on cell survival and cardiomyocyte metabolism (55). Clinical studies on the use of corticosteroids in patients with myocardial infarction have produced conflicting results and, in some cases, raised significant concerns regarding the safety of this approach (56),(57). In vivo experiments have suggested that corticosteroid treatment impairs clearance of the infarct from dead cells and may disrupt fibroblast function (58); these effects would be expected to be detrimental in repair of the infarcted heart.

NSAIDs also exert a broad range of anti-inflammatory actions mediated through inhibition of cyclooxygenase. In animal models of myocardial infarction, use of NSAIDs had both beneficial actions (on acute infarct size) and detrimental effects (on the reparative response). Treatment with ibuprofen reduced infarct size (59); the protective effects were presumed due to attenuated leukocyte infiltration (60). However, observations in a canine model of non-reperfused infarction suggested that reduced inflammation in animals treated with NSAIDs is associated with marked thinning of the scar (61). Clinical investigations showed an association between the use of NSAIDs and adverse outcome following myocardial infarction, due at least in part to increased incidence of cardiac rupture (62). Thus, nonselective inhibition of the inflammatory cascade has potentially catastrophic consequences on the reparative response. Based on this concern, current guidelines recommend against the use of broad range anti-inflammatory therapy (corticosteroids and NSAIDs) in patients with acute myocardial infarction (63).

\section{Selective inhibition of inflammatory signaling}

Advances in understanding of the biology of inflammation suggested that targeted inhibition of selected inflammatory pathways may afford protection to the infarcted heart without disturbing the reparative response. Extensive experimental evidence demonstrated that neutralization of specific inflammatory mediators (including leukocyte integrins, endothelial adhesion molecules, cytokines and chemokines) has impressive beneficial effects in large animal models of reperfused myocardial infarction, markedly reducing the size of the 
infarct. Approaches targeting CD11/CD18 integrins seemed particularly promising: the bulk of experimental evidence derived from a wide range of animal models, ranging from rats to primates, showed impressive reduction in infarct size upon treatment with neutralizing antibodies (4),(64),(65),(66),(67),(68),(69). The protective actions were presumed due to reduced infiltration of the infarct with neutrophils (65) and to attenuated neutrophil-induced cardiomyocyte injury. Unfortunately, the beneficial effects of anti-integrin targeting in animal models could not be reproduced in clinical studies. In three small clinical trials, antiintegrin approaches failed to reduce the size of the infarct in patients with myocardial infarction (70),(5),(71). Approaches targeting the complement system, an upstream activator of the innate immune response, were equally disappointing. In the Assessment of Pexelizumab in Acute Myocardial infarction (APEX-AMI) clinical trial, 5745 patients with STEMI received the anti-C5 antibody pexelizumab as an intravenous bolus prior to percutaneous intervention followed by continuous infusion over the next $24 \mathrm{~h}$. Pexelizumab administration did not affect 30-day mortality and the composite endpoint of death, cardiogenic shock and congestive heart failure (72). Moreover, administration of the Pselectin inhibitor inclacumab in patients with acute coronary syndromes reduced the release of enzymes associated with cardiomyocyte necrosis, but was associated with trends towards worse clinical outcome (73),(74). Considering the great enthusiasm generated by the impressive results of the animal model studies, what are the possible causes of these translational failures?

\section{The anti-inflammatory strategies used in clinical trials may have been suboptimal}

Translation of a therapeutic approach from the animal model to the clinical context is not dependent solely on implementation of a sound pathophysiologic concept, but also requires careful planning of the strategy to maximize the likelihood of success. Selection of an appropriate molecular target, identification of an effective therapeutic agent, correct timing and optimal delivery of the agent in the infarcted area are all crucial for successful translation of the approach. Ultimately, understanding the basis for failure of anti-integrin and complement inhibition strategies requires assessment of the effectiveness of these strategies in inhibiting the myocardial inflammatory response. Unfortunately, such data are lacking. In a subgroup of patients enrolled in the APEX-AMI trial, assessment of circulating biomarkers suggested that pexelizumab was not successful in suppressing most indicators of inflammation (75). Although use of circulating biomarkers as a window to the myocardial inflammatory response is inherently problematic, ineffective suppression of inflammation may provide an explanation for the negative trial. Moreover, experimental studies suggested that the protective actions of integrin inhibition on the infarcted myocardium are variable and may be dependent on the specific characteristics of the antibody used (76). Protective actions could only partially be predicted by the extent of inhibition of neutrophil infiltration (76). Future strategies targeting post-infarction inflammation need to include systematic assessment of the effectiveness of the approach in attenuating several distinct aspects of the inflammatory response through a combination of in vivo imaging approaches and analysis of circulating biomarkers. 


\section{Inflammation may not extend cardiomyocyte death following myocardial infarction}

An alternative explanation of the translational failure of anti-inflammatory approaches may be that, despite the abundant evidence in animal models of myocardial infarction, acute inflammatory cardiomyocyte injury may be of limited significance in human myocardial infarction. Considering the intense inflammatory reaction triggered following infarction in both human patients with STEMI and in animal models of infarction, the disconnect between the human clinical studies and the animal model investigations is unlikely to be explained only by species-specific effects, but may reflect the limitations of animal model experiments. First, enthusiasm regarding the effectiveness of anti-inflammatory strategies in myocardial infarction derived by early inhibition experiments in large animal models may have been premature and somewhat misguided. In contrast to the impressive protective effects of antibody neutralization in large animal models, a more recent body of work in genetically targeted mice has challenged the notion that post-infarction inflammation extends ischemic cardiomyocyte injury. Mice lacking P-selectin and ICAM-1 (77), animals with defective IL-1 signaling (19), and MCP-1 knockouts (25) had no significant reduction in infarct size, despite a marked attenuation of the post-infarction inflammatory response.

Second, animal models cannot recapitulate the pathophysiologic complexity and heterogeneity of the clinical context. Outcome in human patients with myocardial infarction is affected by a wide range of factors. Differences in gender, age, genetic profile, the pattern of coronary disease, comorbid conditions (including diabetes, obesity, hypertension and hyperlipidemia), and treatment with various pharmacologic agents have profound effects on the pathophysiologic response to myocardial infarction. In contrast, in a well-designed animal study, the goal is to eliminate variability in order to test a specific hypothesis. Experimental animals are healthy, matched for gender and age and have an identical genetic profile so that the consequences of a very specific genetic or pharmacologic intervention can be studied. For this reason, animal model studies are optimally used to gain pathophysiologic insights and not to predict effectiveness of a therapeutic approach. Experiments in senescent animals illustrate the impact of age on the inflammatory and reparative response following myocardial infarction. Senescent mice exhibited significantly suppressed (and somewhat prolonged) inflammatory activation following myocardial infarction, associated with defective activation of growth factor signaling and impaired collagen deposition (78). Considering that the conclusions on the effectiveness of antiintegrin approaches in myocardial infarction were derived from experimental studies performed in young mammals (known to exhibit very robust inflammatory reactions), the translational failure may reflect, at least in part, the suppressed inflammatory activation in aged human populations presenting with myocardial infarction.

\section{USE OF TARGETED ANTI-INFLAMMATORY STRATEGIES TO IMPROVE REPAIR AND TO REDUCE ADVERSE POST-INFARCTION REMODELING}

The failures of anti-inflammatory strategies in myocardial infarction may reflect the limited role of inflammatory cardiomyocyte injury during the early stages of infarction. However, inflammation is critically involved in repair and remodeling of the infarcted heart. Inflammatory pathways have been implicated in recruitment of progenitor cells that may 
play a crucial role in infarct angiogenesis and cardiac repair (79). Chemokines (such as stromal cell derived factor (SDF)-1/CXCL12 and MCP-3) mediate homing of progenitor cell subpopulations in the infarcted myocardium (80),(81). Growth factors, such as stem cell factor, hepatocyte growth factor and vascular endothelial growth factor are also upregulated in the infarcted myocardium (82),(83) and may be involved in recruitment and activation of stem cell subsets. On the other hand, prolonged or expanded pro-inflammatory signaling may accentuate adverse remodeling by activating proteases, transducing pro-apoptotic cascades in cardiomyocytes, and promoting matrix degradation. Extensive experimental work suggests that overactive, temporally prolonged (30), or spatially expanded (42) inflammation may cause dilative remodeling following myocardial infarction. Highlyselective approaches to inhibit inflammation-driven protease activation and to promote recruitment of reparative cells may exert beneficial actions on the infarcted heart by stimulating repair, by reducing adverse remodeling and by preventing the development of post-infarction heart failure. Several inflammatory mediators have shown promise as therapeutic targets.

\section{THE CHEMOKINES}

The chemokines are a large family of small $(8-14 \mathrm{kDa})$ chemotactic cytokines with a crucial role in regulating immune function and inflammatory responses (84). On a structural basis, chemokines are classified into 4 subfamilies according to the presence of one or more aminoacids between the $\mathrm{N}$-terminal cysteine residues region $\left(\mathrm{CC}, \mathrm{CXC}, \mathrm{CX}_{3} \mathrm{C}\right.$ and $\mathrm{XC}$ subfamilies). Most chemokines belong to $\mathrm{CC}$ and $\mathrm{CXC}$ subfamilies. The structural differences between the chemokines have important functional implications. $\mathrm{CC}$ chemokines are potent mononuclear cell chemoattractants, whereas CXC chemokines that contain the ELR motif preceding the first aminoterminal cysteine mediate chemotactic recruitment of neutrophils (85).

Experimental studies in animal models of myocardial infarction demonstrated that several members of the chemokine family are rapidly and consistently upregulated in the infarcted heart and may play an important role in regulation of the post-infarction inflammatory response (23). Certain members of the family, including MCP-1/CCL2 and SDF-1/CXCL12 have shown promise as potential therapeutic targets. The findings of experimental studies targeting chemokine family members in myocardial infarction are summarized in Table 1.

\section{CC chemokines}

The CC chemokine MCP-1/CCL2 is rapidly upregulated in the infarcted myocardium and is predominantly expressed in vascular endothelial cells (86). Genetic disruption of MCP-1, or its receptor CCR2, attenuated adverse remodeling following myocardial infarction, inhibiting recruitment of pro-inflammatory monocytes and decreasing cytokine expression in the infarct (25),(87). In a model of non-reperfused infarction, anti-MCP-1 therapy exerted beneficial actions on the infarcted ventricle, reducing mortality, attenuating chamber dilation, and improving systolic function (88). Thus, experimental observations suggest that MCP-1/CCL2 may be a promising therapeutic target following myocardial infarction. However, a word of caution should be raised by observations suggesting that genetic disruption of MCP-1 results in impaired phagocytosis of dead cardiomyocytes, and delayed 
formation of granulation tissue (89),(90). These defects may reflect decreased recruitment of monocytes and impaired macrophage maturation (25). The clinical consequences of impaired clearance of the infarct from dead cells cannot be predicted. Persistence of nonphagocytosed necrotic cardiomyocytes in the infarcted region may have adverse consequences on cardiac function and may be associated with dysrhythmic events in human patients with infarction.

A recent study suggested that inhibition of the CC chemokine CCL5/RANTES (regulated on activation, normal $\mathrm{T}$ cell expressed and secreted) may exert cardioprotective actions (91). RANTES neutralization decreased the size of the infarct and improved cardiac function 3 weeks after infarction, reducing expression of matrix metalloproteinase (MMP)-9. Whether RANTES mediates recruitment a specific subset of pro-inflammatory mononuclear cells, or promotes a matrix-degrading phenotype in leukocytes infiltrating the infarct remains unknown. Although MCP-1 and RANTES may be promising therapeutic targets, broad inhibition of CC chemokines may have detrimental actions. In a mouse model of reperfused infarction, genetic disruption of the $\mathrm{CC}$ chemokine receptor 5 (CCR5) was associated with accentuated dilative remodeling, presumed due to impaired recruitment of inhibitory monocyte subsets and of regulatory T cells (Tregs) (92). Thus, certain chemokinechemokine receptor interactions may be important in repression and resolution of postinfarction inflammation through recruitment of anti-inflammatory leukocyte subpopulations.

\section{ELR+ CXC chemokines}

Although ELR+ CXC chemokines are markedly upregulated in the healing infarct and mediate neutrophil infiltration (24),(93), their potential therapeutic role has not been systematically studied. Early experiments suggested that IL-8/CXCL8 inhibition in rabbits undergoing ischemia/reperfusion protocols reduced infarct size; surprisingly the beneficial effects were not associated with attenuated neutrophil infiltration (94). Enthusiasm about neutrophil chemoattractant chemokines as therapeutic targets in myocardial infarction was dampened by the translational failures of anti-integrin approaches. However, a recent investigation in a mouse model of myocardial ischemia/reperfusion suggested that treatment with evasin-3, a protein that binds and neutralizes neutrophil chemoattractant CXC chemokines, reduces infarct size by attenuating leukocyte recruitment (95).

\section{SDF-1}

The ELR-negative CXC chemokine SDF-1/CXCL12 has potent angiogenic properties, activates pro-survival pathways in cardiomyocytes, and enhances the regenerative capacity of progenitor cells (96). Thus, it is not surprising that treatment with SDF-1 has been considered as a therapeutic strategy for patients with myocardial infarction. The effectiveness of SDF-1 therapy is supported by extensive experimental evidence. Treatment with SDF-1 reduced infarct size, promoting cardiomyocyte survival and accentuating angiogenesis in experimental models of myocardial infarction (97),(98). Several protective mechanisms have been suggested. First, SDF-1-induced angiogenesis in the infarct and in the border zone may improve the quality of the scar attenuating systolic dysfunction. Second, SDF-1 may exert direct anti-apoptotic actions on cardiomyocytes or may promote chemotaxis of a CXCR4+ myeloid cell subset that secretes cytoprotective mediators (99). 
Third, SDF-1 may promote repair and regeneration through recruitment of progenitor cells. Extensive evidence suggests that SDF-1 is critically implicated in mobilization and trafficking of hematopoietic stem cells (100), and mediates homing of endothelial progenitor cells in ischemic tissues (80).

Recent studies have tested novel synthetic analogs of SDF-1 in both rodent and large animal models of myocardial infarction. Injection of a biomimetic hydrogel containing a combination of SDF-1 and angiogenic peptides reduced the size of the infarct and improved angiogenesis in a rat model of myocardial infarction (101). In both rat and ovine models, administration of a bioengineered SDF-1 analog in the infarct border zone induced chemotaxis of endothelial progenitor cells and preserved ventricular function, improving left ventricular mechanics $(102,103)$. Although these experimental studies are promising, it should be emphasized that SDF-1 may also exert pro-inflammatory actions. The pleiotropic, cell-specific and context-dependent actions of SDF-1 are highlighted by the conflicting observations reported in SDF-1 antagonism studies. Some investigations showed that SDF-1 inhibition accentuated dysfunction (supporting the protective actions of the chemokine revealed by the gain-of-function approaches) (104), whereas other studies suggested beneficial effects (105), (106).

\section{Fractalkine/CX3CL1}

The CX3C chemokine fractalkine exists in membrane-anchored and soluble forms and may regulate trafficking and function of immune cells. Its role in myocardial infarction remains poorly understood. In a mouse model of myocardial infarction, fractalkine expression was markedly increased in the viable remodeling myocardium (107); fractalkine inhibition delayed progression of chamber dilation, attenuating pro-inflammatory and matrixdegrading pathways (108). Thus, fractalkine may hold promise as a therapeutic target to attenuate adverse post-infarction remodeling.

\section{THE CYTOKINES}

\section{Targeting the IL-1 system}

The prototypical pro-inflammatory cytokine IL-1 plays a crucial role in stimulation of the post-infarction inflammatory response and is involved in the pathogenesis of cardiac remodeling. Thus, targeting the IL-1 signaling cascade may be a promising therapeutic target for patients with myocardial infarction. In experimental models of myocardial infarction, IL-1a is released by dying cardiomyocytes (9), whereas IL- $1 \beta$ synthesis is markedly upregulated following infarction (16), and is predominantly localized in leukocytes and vascular cells (109). Both genetic and pharmacologic strategies disrupting IL-1 signaling have been shown to protect the infarcted heart from adverse remodeling. Genetic loss of the type $1 \mathrm{IL}-1$ receptor (IL-1R1) attenuates dilation of the infarcted heart, reducing adverse remodeling (19). Pharmacologic approaches targeting the IL-1 system have also been tested in models of myocardial infarction. The availability of safe and effective pharmacologic strategies to inhibit IL-1 signaling in human patients provides promising therapeutic tools. Anakinra, a non-glycosylated recombinant form of interleukin-1 receptor antagonist (IL-1Ra), binds to the type $1 \mathrm{IL}-1$ receptor without activating a signaling 
response, thus functioning as a competitive inhibitor for both IL-1a and IL-1 $\beta$. Anakinra has been approved for treatment of patients with rheumatoid arthritis who fail to respond to disease modifying agents. Anti-IL-1 $\beta$ antibodies (such as canakinumab) provide more selective options, specifically targeting IL- $\beta$ signaling and have been approved for treatment of autoinflammatory diseases and certain forms of inflammatory arthritides. Treatment with anakinra reduced chamber dilation in a rat model of myocardial infarction (110); administration of an anti-IL-1 $\beta$ antibody in a mouse model of non-reperfused infarction also exerted protective actions (111). The protective effects of IL-1 blockade may be only in part mediated through reduction in the size of the infarct. Attenuation of IL-1-driven protease activation in the cardiac interstitium may be implicated in protection from adverse remodeling.

Small clinical trials have tested the effectiveness of IL-1 inhibition in patients with myocardial infarction. Pilot studies have suggested that anakinra can be safely administered as a 2-week course in patients with STEMI and may attenuate adverse remodeling, while protecting from the development of post-infarction heart failure (112),(113),(114). Because IL-1 has been implicated in the pathogenesis of the vulnerable plaque, a large clinical trial is currently underway to examine the effectiveness of IL- $1 \beta$ antibody inhibition in prevention of cardiovascular events in post-myocardial infarction patients with accentuated systemic inflammatory responses (115).

Although both experimental and early clinical findings suggest that IL-1 inhibition may hold promise for treatment of patients with myocardial infarction, a word of caution should be raised regarding cytokine inhibition in patients with heart disease. Cytokines are notoriously pleiotropic and multifunctional and are known to exert a wide range of context-dependent actions on all cell types involved in cardiac injury and repair. In the infarcted and remodeling heart, cytokines may exert both beneficial and detrimental effects; thus, prediction of the consequences of cytokine inhibition in the clinical context is challenging. The failure of anti-TNF strategies in patients with heart failure highlights the challenges in implementation of targeted anti-cytokine approaches in patients with cardiovascular disease. However, it should be noted that, in contrast to TNF-a, IL-1 is not known to exert protective actions on cardiomyocytes. Studies in patients with rheumatoid arthritis suggest protective actions of anakinra on myocardial function (116),(117).

\section{Targeting the TGF- $\beta$ cascade}

Members of the TGF- $\beta$ family are critically involved in regulation of inflammation and fibrosis in a wide range of pathophysiologic conditions (118). It has been suggested that, following myocardial infarction, TGF- $\beta$ may serve as the "master switch" that de-activates inflammatory macrophages, while promoting fibrosis (119). Clearly, this concept represents an oversimplification. TGF- $\beta$ modulates phenotype and function of all cell types involved in cardiac repair, activating both Smad-dependent and Smad-independent signaling (120), (121). The effects of TGF- $\beta$ inhibition may be dependent on timing: early neutralization of TGF- $\beta$ may prolong inflammation and enhance the incidence of cardiac rupture; late suppression may attenuate pro-fibrotic signaling improving diastolic function. Because TGF- $\beta$ plays an important role in preservation of cardiovascular homeostasis, targeting the 
TGF- $\beta$ system in heart failure may carry significant risks, promoting aneurysmal rupture in vulnerable patients (122),(123),(124). Dissection of downstream signaling effectors and identification of specific TGF- $\beta$-activated pathways associated with post-infarction remodeling and dysfunction are needed to design safe and effective therapy for patients with myocardial infarction.

\section{Do inflammatory mediators transduce cytoprotective and regenerative signals?}

Identification of cytoprotective and regenerative actions of leukocyte subsets contributes an additional layer of complexity to the effects of inflammatory cells on the infarcted heart (125). Experiments in models of neonatal cardiac injury suggested that subpopulations of macrophages with unique phenotypic profiles may promote cardiomyocyte proliferation activating a regenerative program (126),(127). The signals that may drive macrophages towards a regenerative phenotype remain unknown. In adult mice, a recent investigation identified myeloid-derived growth factor (MYDGF), as a novel mediator released by a subset of CXCR4-expressing macrophages, that protects cardiomyocytes from ischemic death (99). These findings suggest that inflammatory cells recruited in the infarcted heart not only debride the wound and contribute to scar formation, but may also exert direct protective actions on cardiomyocytes, and may hold the key to cardiac regeneration.

\section{CHALLENGES IN IMPLEMENTATION OF ANTI-INFLAMMATORY STRATEGIES IN PATIENTS WITH ACUTE MYOCARDIAL INFARCTION}

Inflammatory mediators exert a wide range of diverse functions on the infarcted heart. The involvement of inflammatory cells and their secretory products in both injurious and protective effects complicates our efforts to design effective therapy for patients with myocardial infarction. Experimental studies in animal models of myocardial infarction have identified several promising therapeutic targets. However, the failures of the anti-integrin and complement inhibition approaches, despite strong experimental evidence supporting their effectiveness, have generated skepticism regarding our ability to translate promising animal findings into clinical applications.

It should be emphasized that investigations using animal models are essential for dissection of the pathophysiologic mechanisms, but have limited value in predicting success of a therapeutic intervention in the clinical context. As discussed in the previous section, the complexities of the clinical context cannot be simulated in an experimental model. In view of these challenges, how can we optimally use insights from animal models to design effective strategies targeting the inflammatory response in human patients with myocardial infarction? Considering the pathophysiologic heterogeneity of STEMI patients that may explain differences in susceptibility to adverse remodeling, there is a need to identify patients with overactive post-infarction inflammatory responses that may benefit from targeted anti-inflammatory strategies (37),(128). Certain patient subpopulations, such as diabetics and the elderly, may exhibit dysregulated inflammatory reactions following myocardial infarction that may be responsible for accentuated remodeling and worse dysfunction. For example, diabetics have an increased incidence of heart failure following myocardial infarction despite a smaller infarct size and comparable systolic dysfunction 
(129). Development of post-infarction heart failure in diabetics is associated with diastolic dysfunction (130). In mice, diabetes and obesity are associated with cardiac fibrosis, hypertrophy and overactive myocardial TGF- $\beta /$ Smad signaling (124),(131),(43). A link between diabetes-associated TGF- $\beta$ activation and fibrotic remodeling of the infarcted heart is plausible; thus, in these patients targeting the TGF- $\beta$ system may be a promising therapeutic strategy. On the other hand, persistently increased circulating levels of proinflammatory mediators (such as MCP-1/CCL2) are associated with worse prognosis in patients with acute coronary syndromes. Targeted inhibition of inflammation may be effective in patients with defective negative regulation of pro-inflammatory signaling that may exhibit evidence of prolonged inflammatory activation Biomarkers and imaging approaches may be used to obtain information on activation of inflammatory pathways in each patient, in order to personalize treatment options.

\section{CONCLUDING REMARKS}

Activation of inflammatory cascades in the infarcted heart stimulates a range of cellular responses that clear the wound from dead cells and promote repair, but may also extend injury and cause adverse remodeling of the ventricle. Progress in understanding the cellular effectors and molecular signals regulating post-infarction inflammation has not yet translated into effective therapy. Future research should dissect protective and detrimental inflammatory pathways in animal models, while expanding our understanding of the human pathophysiology. Identification and validation of biomarkers that may reflect specific perturbations of the inflammatory response in human patients may provide much-needed pathophysiologic guidance for implementation of personalized treatment approaches.

\section{ACKNOWLEDGMENTS}

Dr Frangogiannis' laboratory is supported by NIH grants R01 HL76246 and R01 HL85440. Ilaria Russo is supported by training grants from the Fondazione Cassa di Risparmio di Lucca and the Fondazione Banca del Monte di Lucca.

\section{REFERENCES}

1. Reinecke H, Minami E, Zhu WZ, Laflamme MA. Cardiogenic differentiation and transdifferentiation of progenitor cells. Circ Res. 2008; 103:1058-1071. [PubMed: 18988903]

2. Frangogiannis NG. The immune system and the remodeling infarcted heart: cell biological insights and therapeutic opportunities. J Cardiovasc Pharmacol. 2014; 63:185-195. [PubMed: 24072174]

3. Entman ML, Youker K, Shoji T, et al. Neutrophil induced oxidative injury of cardiac myocytes. A compartmented system requiring CD11b/CD18-ICAM-1 adherence. J Clin Invest. 1992; 90:13351345. [PubMed: 1357003]

4. Christia P, Frangogiannis NG. Targeting inflammatory pathways in myocardial infarction. Eur J Clin Invest. 2013; 43:986-995. [PubMed: 23772948]

5. Faxon DP, Gibbons RJ, Chronos NA, Gurbel PA, Sheehan F. The effect of blockade of the CD11/ CD18 integrin receptor on infarct size in patients with acute myocardial infarction treated with direct angioplasty: the results of the HALT-MI study. J Am Coll Cardiol. 2002; 40:1199-1204. [PubMed: 12383565]

6. Frangogiannis NG. The mechanistic basis of infarct healing. Antioxid Redox Signal. 2006; 8:19071939. [PubMed: 17034340]

7. Andrassy M, Volz HC, Igwe JC, et al. High-mobility group box-1 in ischemia-reperfusion injury of the heart. Circulation. 2008; 117:3216-3226. [PubMed: 18574060] 
8. Chen C, Feng Y, Zou L, et al. Role of extracellular RNA and TLR3-Trif signaling in myocardial ischemia-reperfusion injury. J Am Heart Assoc. 2014; 3:e000683. [PubMed: 24390148]

9. Lugrin J, Parapanov R, Rosenblatt-Velin N, et al. Cutting Edge: IL-1alpha Is a Crucial Danger Signal Triggering Acute Myocardial Inflammation during Myocardial Infarction. J Immunol. 2015; 194:499-503. [PubMed: 25505286]

10. Huebener P, Abou-Khamis T, Zymek P, et al. CD44 Is Critically Involved in Infarct Healing by Regulating the Inflammatory and Fibrotic Response. J Immunol. 2008; 180:2625-2633. [PubMed: 18250474]

11. Arslan F, de Kleijn DP, Pasterkamp G. Innate immune signaling in cardiac ischemia. Nat Rev Cardiol. 2011; 8:292-300. [PubMed: 21448140]

12. Zhang W, Lavine KJ, Epelman S, et al. Necrotic myocardial cells release damage-associated molecular patterns that provoke fibroblast activation in vitro and trigger myocardial inflammation and fibrosis in vivo. J Am Heart Assoc. 2015:4.

13. Hill JH, Ward PA. The phlogistic role of C3 leukotactic fragments in myocardial infarcts of rats. J Exp Med. 1971; 133:885-900. [PubMed: 4993831]

14. Frangogiannis NG. The immune system and cardiac repair. Pharmacol Res. 2008; 58:88-111. [PubMed: 18620057]

15. De Hoog VC, Timmers L, Van Duijvenvoorde A, et al. Leucocyte expression of complement C5a receptors exacerbates infarct size after myocardial reperfusion injury. Cardiovasc Res. 2014; 103:521-529. [PubMed: 24935433]

16. Dewald O, Ren G, Duerr GD, et al. Of mice and dogs: species-specific differences in the inflammatory response following myocardial infarction. Am J Pathol. 2004; 164:665-677. [PubMed: 14742270]

17. Frangogiannis NG, Lindsey ML, Michael LH, et al. Resident cardiac mast cells degranulate and release preformed TNF-alpha, initiating the cytokine cascade in experimental canine myocardial ischemia/reperfusion. Circulation. 1998; 98:699-710. [PubMed: 9715863]

18. Kukielka GL, Smith CW, Manning AM, Youker KA, Michael LH, Entman ML. Induction of interleukin-6 synthesis in the myocardium Potential role in postreperfusion inflammatory injury. Circulation. 1995; 92:1866-1875. [PubMed: 7671371]

19. Bujak M, Dobaczewski M, Chatila K, et al. Interleukin-1 receptor type I signaling critically regulates infarct healing and cardiac remodeling. Am J Pathol. 2008; 173:57-67. [PubMed: 18535174]

20. Saxena A, Chen W, Su Y, et al. IL-1 Induces Proinflammatory Leukocyte Infiltration and Regulates Fibroblast Phenotype in the Infarcted Myocardium. J Immunol. 2013; 191:4838-4848. [PubMed: 24078695]

21. Mezzaroma E, Toldo S, Farkas D, et al. The inflammasome promotes adverse cardiac remodeling following acute myocardial infarction in the mouse. Proc Natl Acad Sci U S A. 2011; 108:1972519730. [PubMed: 22106299]

22. Kawaguchi M, Takahashi M, Hata T, et al. Inflammasome activation of cardiac fibroblasts is essential for myocardial ischemia/reperfusion injury. Circulation. 2011; 123:594-604. [PubMed: 21282498]

23. Frangogiannis NG. Chemokines in ischemia and reperfusion. Thromb Haemost. 2007; 97:738-747. [PubMed: 17479184]

24. Ivey CL, Williams FM, Collins PD, Jose PJ, Williams TJ. Neutrophil chemoattractants generated in two phases during reperfusion of ischemic myocardium in the rabbit Evidence for a role for C5a and interleukin-8. J Clin Invest. 1995; 95:2720-2728. [PubMed: 7769111]

25. Dewald O, Zymek P, Winkelmann K, et al. CCL2/Monocyte Chemoattractant Protein-1 regulates inflammatory responses critical to healing myocardial infarcts. Circ Res. 2005; 96:881-889. [PubMed: 15774854]

26. Nahrendorf M, Swirski FK, Aikawa E, et al. The healing myocardium sequentially mobilizes two monocyte subsets with divergent and complementary functions. J Exp Med. 2007; 204:3037-3047. [PubMed: 18025128] 
27. Zouggari Y, Ait-Oufella H, Bonnin P, et al. B lymphocytes trigger monocyte mobilization and impair heart function after acute myocardial infarction. Nat Med. 2013; 19:1273-1280. [PubMed: 24037091]

28. Wan E, Yeap XY, Dehn S, et al. Enhanced efferocytosis of apoptotic cardiomyocytes through myeloid-epithelial-reproductive tyrosine kinase links acute inflammation resolution to cardiac repair after infarction. Circ Res. 2013; 113:1004-1012. [PubMed: 23836795]

29. Lorchner H, Poling J, Gajawada P, et al. Myocardial healing requires Reg3beta-dependent accumulation of macrophages in the ischemic heart. Nat Med. 2015; 21:353-362. [PubMed: 25751817]

30. Chen W, Saxena A, Li N, et al. Endogenous IRAK-M attenuates postinfarction remodeling through effects on macrophages and fibroblasts. Arterioscler Thromb Vasc Biol. 2012; 32:2598-2608. [PubMed: 22995519]

31. Libby P, Nahrendorf M, Swirski FK. Monocyte heterogeneity in cardiovascular disease. Seminars in immunopathology. 2013; 35:553-562. [PubMed: 23839097]

32. Weirather J, Hofmann UD, Beyersdorf N, et al. Foxp3+ CD4+ T cells improve healing after myocardial infarction by modulating monocyte/macrophage differentiation. Circ Res. 2014; 115:55-67. [PubMed: 24786398]

33. Saxena A, Dobaczewski M, Rai V, et al. Regulatory T cells are recruited in the infarcted mouse myocardium and may modulate fibroblast phenotype and function. Am J Physiol Heart Circ Physiol. 2014; 307:H1233-H1242. [PubMed: 25128167]

34. Ben-Mordechai T, Holbova R, Landa-Rouben N, et al. Macrophage subpopulations are essential for infarct repair with and without stem cell therapy. J Am Coll Cardiol. 2013; 62:1890-1901. [PubMed: 23973704]

35. Ma Y, Halade GV, Zhang J, et al. Matrix metalloproteinase-28 deletion exacerbates cardiac dysfunction and rupture after myocardial infarction in mice by inhibiting M2 macrophage activation. Circ Res. 2013; 112:675-688. [PubMed: 23261783]

36. Frangogiannis NG. The reparative function of cardiomyocytes in the infarcted myocardium. Cell Metab. 2015; 21:797-798. [PubMed: 26039445]

37. Frangogiannis NG. The inflammatory response in myocardial injury, repair, and remodelling. Nat Rev Cardiol. 2014; 11:255-265. [PubMed: 24663091]

38. Frangogiannis NG, Michael LH, Entman ML. Myofibroblasts in reperfused myocardial infarcts express the embryonic form of smooth muscle myosin heavy chain (SMemb). Cardiovasc Res. 2000; 48:89-100. [PubMed: 11033111]

39. Willems IE, Havenith MG, De Mey JG, Daemen MJ. The alpha-smooth muscle actin-positive cells in healing human myocardial scars. Am J Pathol. 1994; 145:868-875. [PubMed: 7943177]

40. Ruiz-Villalba A, Simon AM, Pogontke C, et al. Interacting resident epicardium-derived fibroblasts and recruited bone marrow cells form myocardial infarction scar. J Am Coll Cardiol. 2015; 65:2057-2066. [PubMed: 25975467]

41. Frangogiannis NG. Matricellular proteins in cardiac adaptation and disease. Physiol Rev. 2012; 92:635-688. [PubMed: 22535894]

42. Frangogiannis NG, Ren G, Dewald O, et al. The critical role of endogenous Thrombospondin (TSP)-1 in preventing expansion of healing myocardial infarcts. Circulation. 2005; 111:29352942. [PubMed: 15927970]

43. Gonzalez-Quesada C, Cavalera M, Biernacka A, et al. Thrombospondin-1 induction in the diabetic myocardium stabilizes the cardiac matrix in addition to promoting vascular rarefaction through angiopoietin-2 upregulation. Circ Res. 2013; 113:1331-1344. [PubMed: 24081879]

44. Oka T, Xu J, Kaiser RA, et al. Genetic manipulation of periostin expression reveals a role in cardiac hypertrophy and ventricular remodeling. Circ Res. 2007; 101:313-321. [PubMed: 17569887]

45. Shinde AV, Frangogiannis NG. Fibroblasts in myocardial infarction: A role in inflammation and repair. J Mol Cell Cardiol. 2014; 70C:74-82. [PubMed: 24321195]

46. Dobaczewski M, Bujak M, Li N, et al. Smad3 signaling critically regulates fibroblast phenotype and function in healing myocardial infarction. Circ Res. 2010; 107:418-428. [PubMed: 20522804] 
47. Cohn JN, Colucci W. Cardiovascular effects of aldosterone and post-acute myocardial infarction pathophysiology. Am J Cardiol. 2006; 97:4F-12F.

48. Schnee JM, Hsueh WA. Angiotensin II, adhesion, and cardiac fibrosis. Cardiovasc Res. 2000; 46:264-268. [PubMed: 10773230]

49. Bujak M, Dobaczewski M, Gonzalez-Quesada C, et al. Induction of the CXC chemokine interferon-gamma-inducible protein 10 regulates the reparative response following myocardial infarction. Circ Res. 2009; 105:973-983. [PubMed: 19797174]

50. Saxena A, Bujak M, Frunza O, et al. CXCR3-independent actions of the CXC chemokine CXCL10 in the infarcted myocardium and in isolated cardiac fibroblasts are mediated through proteoglycans. Cardiovasc Res. 2014; 103:217-227. [PubMed: 24891401]

51. Frangogiannis NG. Regulation of the inflammatory response in cardiac repair. Circ Res. 2012; 110:159-173. [PubMed: 22223212]

52. Romson JL, Hook BG, Kunkel SL, Abrams GD, Schork MA, Lucchesi BR. Reduction of the extent of ischemic myocardial injury by neutrophil depletion in the dog. Circulation. 1983; 67:1016-1023. [PubMed: 6831665]

53. Chatelain P, Latour JG, Tran D, de Lorgeril M, Dupras G, Bourassa M. Neutrophil accumulation in experimental myocardial infarcts: relation with extent of injury and effect of reperfusion. Circulation. 1987; 75:1083-1090. [PubMed: 3568308]

54. Baxter GF. The neutrophil as a mediator of myocardial ischemia-reperfusion injury: time to move on. Basic Res Cardiol. 2002; 97:268-275. [PubMed: 12111036]

55. Libby P, Maroko PR, Bloor CM, Sobel BE, Braunwald E. Reduction of experimental myocardial infarct size by corticosteroid administration. J Clin Invest. 1973; 52:599-607. [PubMed: 4685084]

56. Roberts R, DeMello V, Sobel BE. Deleterious effects of methylprednisolone in patients with myocardial infarction. Circulation. 1976; 53:I204-I206. [PubMed: 1253361]

57. Giugliano GR, Giugliano RP, Gibson CM, Kuntz RE. Meta-analysis of corticosteroid treatment in acute myocardial infarction. Am J Cardiol. 2003; 91:1055-1059. [PubMed: 12714146]

58. Kloner RA, Fishbein MC, Lew H, Maroko PR, Braunwald E. Mummification of the infarcted myocardium by high dose corticosteroids. Circulation. 1978; 57:56-63. [PubMed: 618398]

59. Kirlin PC, Romson JL, Pitt B, Abrams GD, Schork MA, Lucchesi BR. Ibuprofen-mediated infarct size reduction: effects on regional myocardial function in canine myocardial infarction. Am $\mathrm{J}$ Cardiol. 1982; 50:849-856. [PubMed: 7124645]

60. Flynn PJ, Becker WK, Vercellotti GM, et al. Ibuprofen inhibits granulocyte responses to inflammatory mediators. A proposed mechanism for reduction of experimental myocardial infarct size. Inflammation. 1984; 8:33-44. [PubMed: 6325343]

61. Hammerman H, Kloner RA, Schoen FJ, Brown EJ Jr, Hale S, Braunwald E. Indomethacin-induced scar thinning after experimental myocardial infarction. Circulation. 1983; 67:1290-1295. [PubMed: 6851023]

62. Silverman HS, Pfeifer MP. Relation between use of anti-inflammatory agents and left ventricular free wall rupture during acute myocardial infarction. Am J Cardiol. 1987; 59:363-364. [PubMed: 3812291]

63. Steg PG, James SK, et al. Task Force on the management of STseamiotESoC. ESC Guidelines for the management of acute myocardial infarction in patients presenting with ST-segment elevation. Eur Heart J. 2012; 33:2569-2619. [PubMed: 22922416]

64. Arai M, Lefer DJ, So T, DiPaula A, Aversano T, Becker LC. An anti-CD18 antibody limits infarct size and preserves left ventricular function in dogs with ischemia and 48-hour reperfusion. $\mathrm{J}$ Am Coll Cardiol. 1996; 27:1278-1285. [PubMed: 8609356]

65. Aversano T, Zhou W, Nedelman M, Nakada M, Weisman H. A chimeric IgG4 monoclonal antibody directed against CD18 reduces infarct size in a primate model of myocardial ischemia and reperfusion. J Am Coll Cardiol. 1995; 25:781-788. [PubMed: 7860929]

66. Lefer DJ, Shandelya SM, Serrano CV Jr, Becker LC, Kuppusamy P, Zweier JL. Cardioprotective actions of a monoclonal antibody against CD-18 in myocardial ischemia-reperfusion injury. Circulation. 1993; 88:1779-1787. [PubMed: 8104739]

67. Ma XL, Tsao PS, Lefer AM. Antibody to CD-18 exerts endothelial and cardiac protective effects in myocardial ischemia and reperfusion. J Clin Invest. 1991; 88:1237-1243. [PubMed: 1680879] 
68. Simpson PJ, Todd RF 3rd, Fantone JC, Mickelson JK, Griffin JD, Lucchesi BR. Reduction of experimental canine myocardial reperfusion injury by a monoclonal antibody (anti-Mo1, antiCD11b) that inhibits leukocyte adhesion. J Clin Invest. 1988; 81:624-629. [PubMed: 3339135]

69. Simpson PJ, Todd RF 3rd, Mickelson JK, et al. Sustained limitation of myocardial reperfusion injury by a monoclonal antibody that alters leukocyte function. Circulation. 1990; 81:226-237. [PubMed: 2153476]

70. Baran KW, Nguyen M, McKendall GR, et al. Double-blind, randomized trial of an anti-CD18 antibody in conjunction with recombinant tissue plasminogen activator for acute myocardial infarction: limitation of myocardial infarction following thrombolysis in acute myocardial infarction (LIMIT AMI) study. Circulation. 2001; 104:2778-2783. [PubMed: 11733394]

71. Rusnak JM, Kopecky SL, Clements IP, et al. An anti-CD11/CD18 monoclonal antibody in patients with acute myocardial infarction having percutaneous transluminal coronary angioplasty (the FESTIVAL study). Am J Cardiol. 2001; 88:482-487. [PubMed: 11524054]

72. Armstrong PW, Granger CB, Adams PX, et al. Pexelizumab for acute ST-elevation myocardial infarction in patients undergoing primary percutaneous coronary intervention: a randomized controlled trial. Jama. 2007; 297:43-51. [PubMed: 17200474]

73. Tardif JC, Tanguay JF, Wright SS, et al. Effects of the P-selectin antagonist inclacumab on myocardial damage after percutaneous coronary intervention for non-ST-segment elevation myocardial infarction: results of the SELECT-ACS trial. J Am Coll Cardiol. 2013; 61:2048-2055. [PubMed: 23500230]

74. Seropian IM, Toldo S, Van Tassell BW, Abbate A. Anti-inflammatory strategies for ventricular remodeling following ST-segment elevation acute myocardial infarction. J Am Coll Cardiol. 2014; 63:1593-1603. [PubMed: 24530674]

75. Martel C, Granger CB, Ghitescu M, et al. Pexelizumab fails to inhibit assembly of the terminal complement complex in patients with ST-elevation myocardial infarction undergoing primary percutaneous coronary intervention Insight from a substudy of the Assessment of Pexelizumab in Acute Myocardial Infarction (APEX-AMI) trial. Am Heart J. 2012; 164:43-51. [PubMed: 22795281]

76. Perez RG, Arai M, Richardson C, et al. Factors modifying protective effect of anti-CD18 antibodies on myocardial reperfusion injury in dogs. Am J Physiol. 1996; 270:H53-H64. [PubMed: 8769734]

77. Briaud SA, Ding ZM, Michael LH, Entman ML, Daniel S, Ballantyne CM. Leukocyte trafficking and myocardial reperfusion injury in ICAM-1/P-selectin-knockout mice. Am J Physiol Heart Circ Physiol. 2001; 280:H60-H67. [PubMed: 11123218]

78. Bujak M, Kweon HJ, Chatila K, Li N, Taffet G, Frangogiannis NG. Aging-related defects are associated with adverse cardiac remodeling in a mouse model of reperfused myocardial infarction. J Am Coll Cardiol. 2008; 51:1384-1392. [PubMed: 18387441]

79. Taghavi S, George JC. Homing of stem cells to ischemic myocardium. Am J Transl Res. 2013; 5:404-411. [PubMed: 23724164]

80. Askari AT, Unzek S, Popovic ZB, et al. Effect of stromal-cell-derived factor 1 on stem-cell homing and tissue regeneration in ischaemic cardiomyopathy. Lancet. 2003; 362:697-703. [PubMed: 12957092]

81. Schenk S, Mal N, Finan A, et al. Monocyte chemotactic protein-3 is a myocardial mesenchymal stem cell homing factor. Stem Cells. 2007; 25:245-251. [PubMed: 17053210]

82. Frangogiannis NG, Perrard JL, Mendoza LH, et al. Stem cell factor induction is associated with mast cell accumulation after canine myocardial ischemia and reperfusion. Circulation. 1998; 98:687-698. [PubMed: 9715862]

83. Li J, Brown LF, Hibberd MG, Grossman JD, Morgan JP, Simons M. VEGF, flk-1, and flt-1 expression in a rat myocardial infarction model of angiogenesis. Am J Physiol. 1996; 270:H1803H1811. [PubMed: 8928889]

84. Griffith JW, Sokol CL, Luster AD. Chemokines and chemokine receptors: positioning cells for host defense and immunity. Annu Rev Immunol. 2014; 32:659-702. [PubMed: 24655300]

85. Clark-Lewis I, Schumacher C, Baggiolini M, Moser B. Structure-activity relationships of interleukin-8 determined using chemically synthesized analogs Critical role of NH2-terminal 
residues and evidence for uncoupling of neutrophil chemotaxis, exocytosis, and receptor binding activities. J Biol Chem. 1991; 266:23128-23134. [PubMed: 1744111]

86. Kumar AG, Ballantyne CM, Michael LH, et al. Induction of monocyte chemoattractant protein-1 in the small veins of the ischemic and reperfused canine myocardium. Circulation. 1997; 95:693700. [PubMed: 9024159]

87. Kaikita K, Hayasaki T, Okuma T, Kuziel WA, Ogawa H, Takeya M. Targeted deletion of CC chemokine receptor 2 attenuates left ventricular remodeling after experimental myocardial infarction. Am J Pathol. 2004; 165:439-447. [PubMed: 15277218]

88. Hayashidani S, Tsutsui H, Shiomi T, et al. Anti-monocyte chemoattractant protein-1 gene therapy attenuates left ventricular remodeling and failure after experimental myocardial infarction. Circulation. 2003; 108:2134-2140. [PubMed: 14517168]

89. Xia Y, Frangogiannis NG. MCP-1/CCL2 as a therapeutic target in myocardial infarction and ischemic cardiomyopathy. Inflamm Allergy Drug Targets. 2007; 6:101-107. [PubMed: 17692033]

90. Becker LC. Yin and yang of MCP-1. Circ Res. 2005; 96:812-814. [PubMed: 15860761]

91. Montecucco F, Braunersreuther V, Lenglet S, et al. CC chemokine CCL5 plays a central role impacting infarct size and post-infarction heart failure in mice. Eur Heart J. 2012; 33:1964-1974. [PubMed: 21606075]

92. Dobaczewski M, Xia Y, Bujak M, Gonzalez-Quesada C, Frangogiannis NG. CCR5 signaling suppresses inflammation and reduces adverse remodeling of the infarcted heart, mediating recruitment of regulatory T cells. Am J Pathol. 2010; 176:2177-2187. [PubMed: 20382703]

93. Chandrasekar B, Smith JB, Freeman GL. Ischemia-reperfusion of rat myocardium activates nuclear factor-KappaB and induces neutrophil infiltration via lipopolysaccharide-induced CXC chemokine. Circulation. 2001; 103:2296-2302. [PubMed: 11342480]

94. Boyle EM Jr, Kovacich JC, Hebert CA, et al. Inhibition of interleukin-8 blocks myocardial ischemia-reperfusion injury. J Thorac Cardiovasc Surg. 1998; 116:114-121. [PubMed: 9671905]

95. Montecucco F, Lenglet S, Braunersreuther V, et al. Single administration of the CXC chemokinebinding protein Evasin-3 during ischemia prevents myocardial reperfusion injury in mice. Arterioscler Thromb Vasc Biol. 2010; 30:1371-1377. [PubMed: 20413731]

96. Frangogiannis NG. The stromal cell-derived factor-1/CXCR4 axis in cardiac injury and repair. J Am Coll Cardiol. 2011; 58:2424-2426. [PubMed: 22115650]

97. Hu X, Dai S, Wu WJ, et al. Stromal cell derived factor-1 alpha confers protection against myocardial ischemia/reperfusion injury: role of the cardiac stromal cell derived factor-1 alpha CXCR4 axis. Circulation. 2007; 116:654-663. [PubMed: 17646584]

98. Saxena A, Fish JE, White MD, et al. Stromal cell-derived factor-1alpha is cardioprotective after myocardial infarction. Circulation. 2008; 117:2224-2231. [PubMed: 18427137]

99. Korf-Klingebiel M, Reboll MR, Klede S, et al. Myeloid-derived growth factor (C19orf10) mediates cardiac repair following myocardial infarction. Nat Med. 2015; 21:140-149. [PubMed: 25581518]

100. Aiuti A, Webb IJ, Bleul C, Springer T, Gutierrez-Ramos JC. The chemokine SDF-1 is a chemoattractant for human CD34+ hematopoietic progenitor cells and provides a new mechanism to explain the mobilization of CD34+ progenitors to peripheral blood. J Exp Med. 1997; 185:111-120. [PubMed: 8996247]

101. Song M, Jang H, Lee J, et al. Regeneration of chronic myocardial infarction by injectable hydrogels containing stem cell homing factor SDF-1 and angiogenic peptide Ac-SDKP. Biomaterials. 2014; 35:2436-2445. [PubMed: 24378015]

102. Macarthur JW Jr, Cohen JE, McGarvey JR, et al. Preclinical evaluation of the engineered stem cell chemokine stromal cell-derived factor 1alpha analog in a translational ovine myocardial infarction model. Circ Res. 2014; 114:650-659. [PubMed: 24366171]

103. MacArthur JW Jr, Purcell BP, Shudo Y, et al. Sustained release of engineered stromal cellderived factor 1-alpha from injectable hydrogels effectively recruits endothelial progenitor cells and preserves ventricular function after myocardial infarction. Circulation. 2013; 128:S79-S86. [PubMed: 24030424] 
104. Dai S, Yuan F, Mu J, et al. Chronic AMD3100 antagonism of SDF-1alpha-CXCR4 exacerbates cardiac dysfunction and remodeling after myocardial infarction. J Mol Cell Cardiol. 2010; 49:587-597. [PubMed: 20655922]

105. Proulx C, El-Helou V, Gosselin H, et al. Antagonism of stromal cell-derived factor-1alpha reduces infarct size and improves ventricular function after myocardial infarction. Pflugers Arch. 2007; 455:241-250. [PubMed: 17520275]

106. Jujo K, Hamada H, Iwakura A, et al. CXCR4 blockade augments bone marrow progenitor cell recruitment to the neovasculature and reduces mortality after myocardial infarction. Proc Natl Acad Sci U S A. 2010; 107:11008-11013. [PubMed: 20534467]

107. Husberg C, Nygard S, Finsen AV, et al. Cytokine expression profiling of the myocardium reveals a role for CX3CL1 (fractalkine) in heart failure. J Mol Cell Cardiol. 2008; 45:261-269. [PubMed: 18585734]

108. Xuan W, Liao Y, Chen B, et al. Detrimental effect of fractalkine on myocardial ischaemia and heart failure. Cardiovasc Res. 2011; 92:385-393. [PubMed: 21840883]

109. Christia P, Bujak M, Gonzalez-Quesada C, et al. Systematic characterization of myocardial inflammation, repair, and remodeling in a mouse model of reperfused myocardial infarction. $\mathrm{J}$ Histochem Cytochem. 2013; 61:555-570. [PubMed: 23714783]

110. Abbate A, Salloum FN, Vecile E, et al. Anakinra, a recombinant human interleukin-1 receptor antagonist, inhibits apoptosis in experimental acute myocardial infarction. Circulation. 2008; 117:2670-2683. [PubMed: 18474815]

111. Toldo S, Mezzaroma E, Van Tassell BW, et al. Interleukin-1beta blockade improves cardiac remodelling after myocardial infarction without interrupting the inflammasome in the mouse. Exp Physiol. 2013; 98:734-745. [PubMed: 23180808]

112. Abbate A, Kontos MC, Grizzard JD, et al. Interleukin-1 blockade with anakinra to prevent adverse cardiac remodeling after acute myocardial infarction (Virginia Commonwealth University Anakinra Remodeling Trial [VCU-ART] Pilot study). Am J Cardiol. 2010; 105:13711377. e1. [PubMed: 20451681]

113. Abbate A, Van Tassell BW, Biondi-Zoccai G, et al. Effects of interleukin-1 blockade with anakinra on adverse cardiac remodeling and heart failure after acute myocardial infarction [from the Virginia Commonwealth University-Anakinra Remodeling Trial (2) (VCU-ART2) pilot study]. Am J Cardiol. 2013; 111:1394-1400. [PubMed: 23453459]

114. Abbate A, Kontos MC, Abouzaki NA, et al. Comparative safety of interleukin-1 blockade with anakinra in patients with ST-segment elevation acute myocardial infarction (from the VCU-ART and VCU-ART2 pilot studies). Am J Cardiol. 2015; 115:288-292. [PubMed: 25482680]

115. Ridker PM, Thuren T, Zalewski A, Libby P. Interleukin-1beta inhibition and the prevention of recurrent cardiovascular events: rationale and design of the Canakinumab Anti-inflammatory Thrombosis Outcomes Study (CANTOS). Am Heart J. 2011; 162:597-605. [PubMed: 21982649]

116. Ikonomidis I, Lekakis JP, Nikolaou M, et al. Inhibition of interleukin-1 by anakinra improves vascular and left ventricular function in patients with rheumatoid arthritis. Circulation. 2008; 117:2662-2669. [PubMed: 18474811]

117. Ikonomidis I, Tzortzis S, Lekakis J, et al. Lowering interleukin-1 activity with anakinra improves myocardial deformation in rheumatoid arthritis. Heart. 2009; 95:1502-1507. [PubMed: 19482847]

118. Biernacka A, Dobaczewski M, Frangogiannis NG. TGF-beta signaling in fibrosis. Growth Factors. 2011; 29:196-202. [PubMed: 21740331]

119. Bujak M, Frangogiannis NG. The role of TGF-beta signaling in myocardial infarction and cardiac remodeling. Cardiovasc Res. 2007; 74:184-195. [PubMed: 17109837]

120. Bujak M, Ren G, Kweon HJ, et al. Essential Role of Smad3 in Infarct Healing and in the Pathogenesis of Cardiac Remodeling. Circulation. 2007; 116:2127-2138. [PubMed: 17967775]

121. Rainer PP, Hao S, Vanhoutte D, et al. Cardiomyocyte-specific transforming growth factor beta suppression blocks neutrophil infiltration, augments multiple cytoprotective cascades, and reduces early mortality after myocardial infarction. Circ Res. 2014; 114:1246-1257. [PubMed: 24573206] 
122. Frangogiannis NG. Targeting the transforming growth factor (TGF)-beta cascade in the remodeling heart: benefits and perils. J Mol Cell Cardiol. 2014; 76:169-171. [PubMed: 25218305]

123. Engebretsen KV, Skardal K, Bjornstad S, et al. Attenuated development of cardiac fibrosis in left ventricular pressure overload by SM16, an orally active inhibitor of ALK5. J Mol Cell Cardiol. 2014; 76:148-157. [PubMed: 25169971]

124. Biernacka A, Cavalera M, Wang J, et al. Smad3 Signaling Promotes Fibrosis, While Preserving Cardiac and Aortic Geometry in Obese Diabetic Mice. Circ Heart Fail. 2015 epub ahead of print 114.001963.

125. Frangogiannis NG. Inflammation in cardiac injury, repair and regeneration. Curr Opin Cardiol. 2015

126. Aurora AB, Porrello ER, Tan W, et al. Macrophages are required for neonatal heart regeneration. J Clin Invest. 2014; 124:1382-1392. [PubMed: 24569380]

127. Lavine KJ, Epelman S, Uchida K, et al. Distinct macrophage lineages contribute to disparate patterns of cardiac recovery and remodeling in the neonatal and adult heart. Proc Natl Acad Sci U S A. 2014; 111:16029-16034. [PubMed: 25349429]

128. Frangogiannis NG. Biomarkers: hopes and challenges in the path from discovery to clinical practice. Transl Res. 2012; 159:197-204. [PubMed: 22424424]

129. Stone PH, Muller JE, Hartwell T, et al. The effect of diabetes mellitus on prognosis and serial left ventricular function after acute myocardial infarction: contribution of both coronary disease and diastolic left ventricular dysfunction to the adverse prognosis. The MILIS Study Group. J Am Coll Cardiol. 1989; 14:49-57. [PubMed: 2661630]

130. Aronson D, Musallam A, Lessick J, et al. Impact of diastolic dysfunction on the development of heart failure in diabetic patients after acute myocardial infarction. Circ Heart Fail. 2010; 3:125131. [PubMed: 19910536]

131. Cavalera M, Wang J, Frangogiannis NG. Obesity, metabolic dysfunction, and cardiac fibrosis: pathophysiological pathways, molecular mechanisms, and therapeutic opportunities. Transl Res. 2014; 164:323-335. [PubMed: 24880146]

132. Liehn EA, Piccinini AM, Koenen RR, et al. A new monocyte chemotactic protein-1/chemokine CC motif ligand-2 competitor limiting neointima formation and myocardial ischemia/reperfusion injury in mice. J Am Coll Cardiol. 2010; 56:1847-1857. [PubMed: 21087715]

133. Projahn D, Simsekyilmaz S, Singh S, et al. Controlled intramyocardial release of engineered chemokines by biodegradable hydrogels as a treatment approach of myocardial infarction. J Cell Mol Med. 2014; 18:790-800. [PubMed: 24512349]

134. Jujo K, Ii M, Sekiguchi H, et al. CXC-chemokine receptor 4 antagonist AMD3100 promotes cardiac functional recovery after ischemia/reperfusion injury via endothelial nitric oxide synthase-dependent mechanism. Circulation. 2013; 127:63-73. [PubMed: 23204107] 


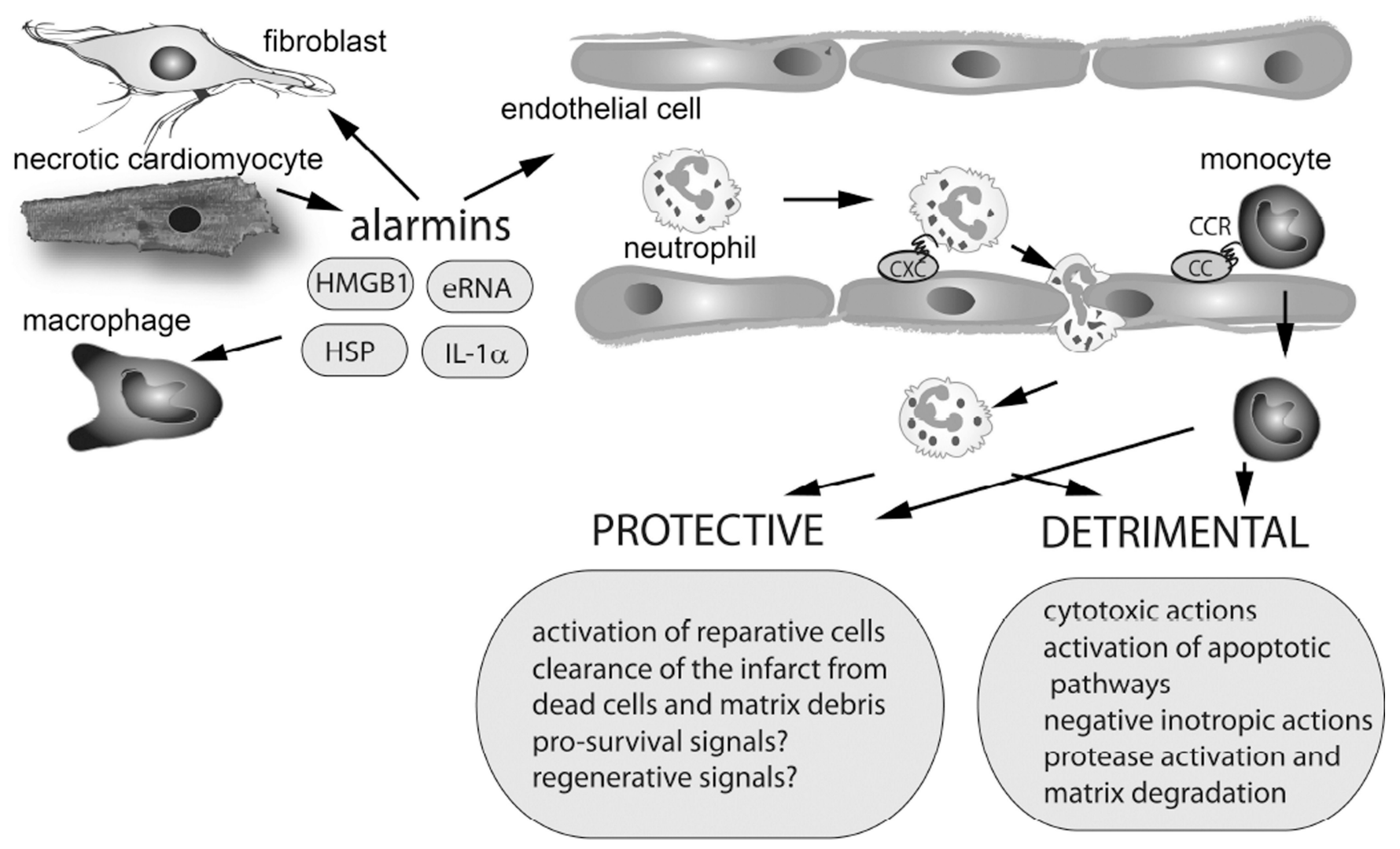

Figure 1.

The post-infarction inflammatory reaction exerts both protective and detrimental actions on the infarcted heart. Necrotic cardiomyocytes release danger signals that activate innate immune responses leading to induction of cytokines and chemokines. CXC and CC Chemokines bind to glycosaminoglycans on the endothelial surface and mediate recruitment of neutrophils and mononuclear cells in the infarcted area. Infiltrating leukocytes exert a wide range of protective and detrimental actions on the infarcted heart. It has been proposed that infiltrating neutrophils may extend ischemic injury exerting cytotoxic, and pro-apoptotic actions on cardiomyocytes. Moreover, leukocyte-derived secretory products may have negative inotropic effects and proteases may increase matrix degradation causing adverse remodeling of the infarcted heart. Other actions of leukocytes may be protective. Thus, leukocyte subsets may phagocytose dead cells and matrix debris and may promote repair by activating endothelial cells and fibroblasts. Recent studies have suggested that subsets of myeloid cells may also exert pro-survival and regenerative actions on cardiomyocytes. 


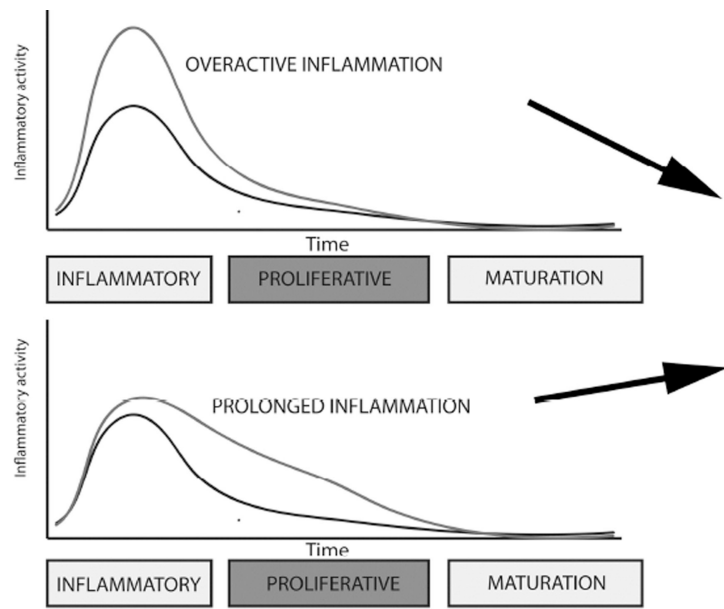

MATRIX DEGRADATION

EXPANSION OF INFLAMMATION

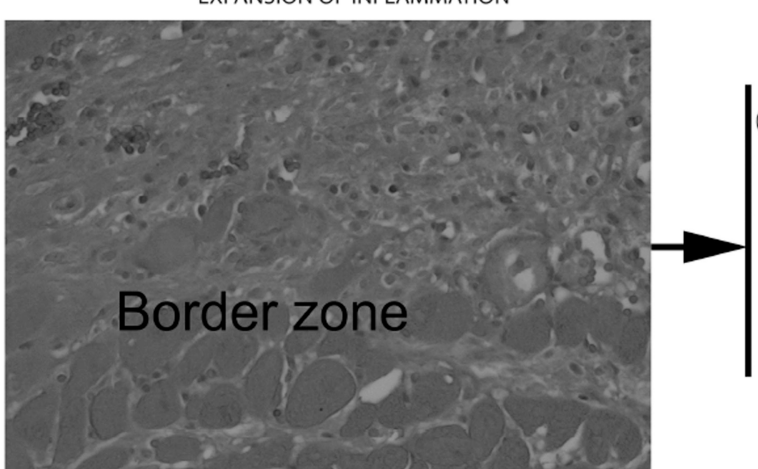

EXTENSION OF CARDIOMYOCYTE INJURY

PROTEASE ACTIVATION

EXPANSION OF FIBROSIS

IN VIABLE AREAS

Figure 2.

The consequences of excessive, prolonged and expanded inflammatory responses on the remodeling infarcted heart. Overactive or prolonged inflammation may accentuate matrix degradation by stimulating protease activation. Increased cytokine expression may increase cardiomyocyte apoptosis and suppress contractility. Defects in spatial containment of the post-infarction inflammatory response may result in extension of inflammatory injury in the viable myocardial areas leading to expansion of fibrosis. Impaired negative regulation of post-infarction inflammation may cause adverse dilative remodeling and accentuate systolic dysfunction. 

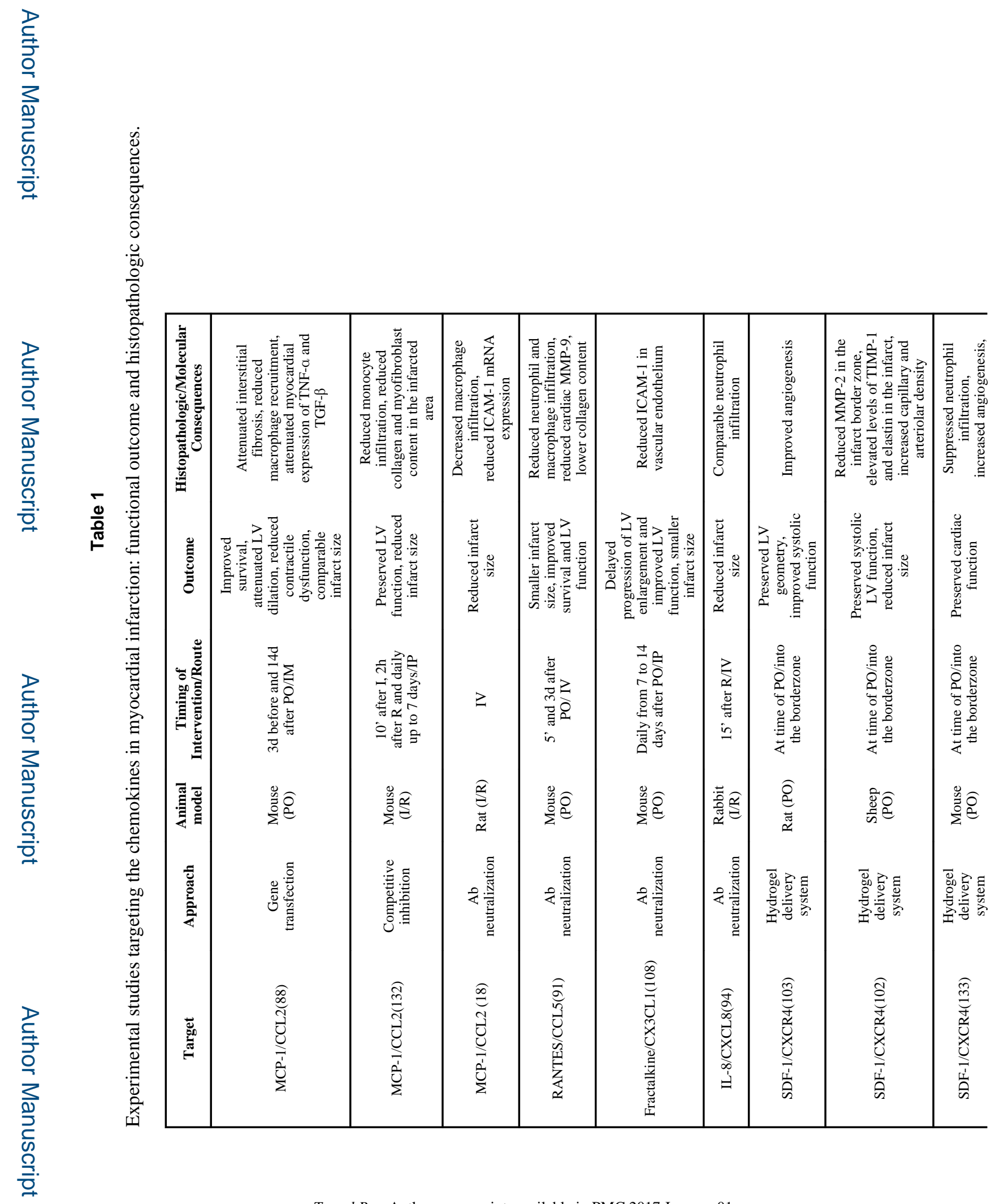

Transl Res. Author manuscript; available in PMC 2017 January 01. 


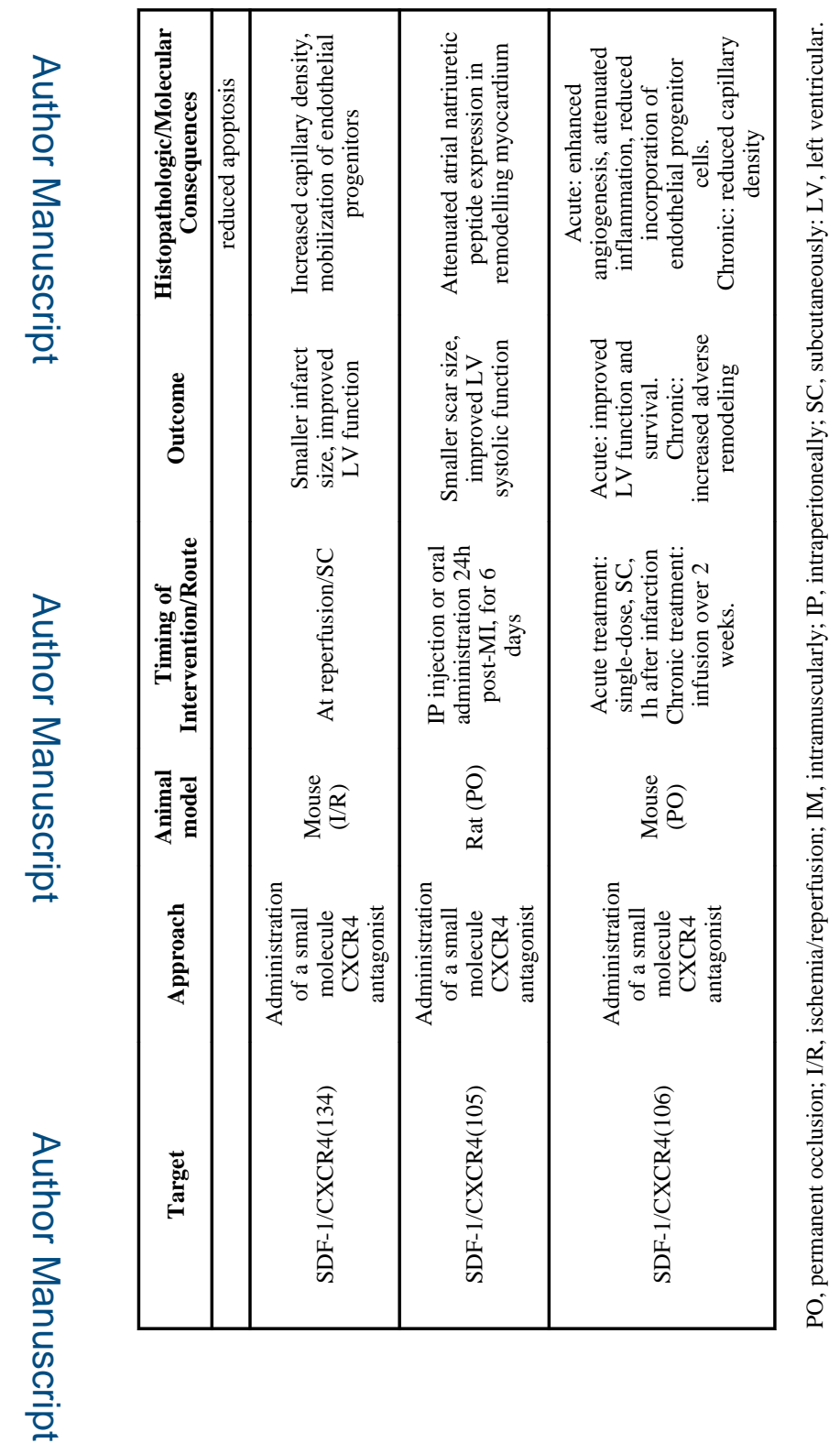

Transl Res. Author manuscript; available in PMC 2017 January 01. 